\title{
Long-term trends in foF 2 over Moscow ionosonde station: Its estimate and origins
}

\author{
FANG HanXian $^{1,2}$, WENG LiBin ${ }^{1 *}$, YANG ShengGao $^{1} \&$ WANG SiCheng ${ }^{1}$ \\ ${ }^{1}$ Institute of Meteorology, People's Liberation Army University of Science and Technology, Nanjing 211101, China; \\ ${ }^{2}$ State Key Laboratory of Space Weather, Chinese Academy of Sciences, Beijing 100190, China
}

Received September 27, 2011; accepted January 5, 2012

\begin{abstract}
We introduce a new approach, using the International Reference Ionosphere 2007 (IRI-2007) model and observations from the Moscow ionosonde station, to analyze the long-term trends of ionospheric foF 2 . Possible origins, whether natural or manmade, are discussed. A small but significant residual foF 2 trend is found, with $-0.76 \mathrm{MHz}$ over the past 50 years, but $-0.2 \mathrm{MHz}$ after eliminating the most variations caused by solar and geomagnetic activities and the variational earth's magnetic field. We find that this slope depends on local time and seasons. There is a pronounced diurnal negative variation in $k$ (annual mean slope of diurnal variations), with much larger absolute values in the morning than during afternoon or evening; the largest $k$ is about -0.0018 per year in spring, and the smallest trend of about -0.0012 per year occurs in winter. Finally, the evidence of crucial influences of geomagnetic activity and the earth's magnetic field on the observed trends, as emphasized by the IRI-2007 empirical model, is confirmed, and the effect of $\mathrm{CO}_{2}$ contributions to the trend is also discussed, by cooling the thermospheric temperature or recombining the electron density.
\end{abstract}

ionosphere, long-term trends, IRI-2007, Moscow

Citation: $\quad$ Fang H X, Weng L B, Yang S G, et al. Long-term trends in foF2 over Moscow ionosonde station: Its estimate and origins. Chin Sci Bull, 2012, 57: 1443-1448, doi: 10.1007/s11434-012-5046-x

Roble and Dickinson [1] studied the atmospheric concentration of greenhouse gases, which has induced global surface air temperature increases, predominantly during recent decades. Long-term (longer than one solar cycle) changes in the ionosphere have also been widely addressed in recent years, using long time-series ionospheric observations [2-5]. Most analyses of the long-term trends are the $\mathrm{F} 2$ region parameters, because the F2-layer observations are most abundant, and the most important parameter is ionospheric foF 2 , which has more than 50 years interval.

Danilov and Mikhailov [2] proposed an approach to reveal the foF 2 trends. They obtained negative trends for all 22 ionospheric stations they studied, and a pronounced dependence of trend magnitude on the geomagnetic latitude. Using this approach, the same researchers [3] analyzed data from northern hemisphere stations, obtaining a consistent

*Corresponding author (email: weng_1986@163.com) picture of the foF 2 trend. This trend varied systematically with local time, season and geomagnetic latitude, and Danilov and Mikhailov suggested that this could be associated with the ionospheric (or geomagnetic) storms. Allon and Martin [4] used neural networks to isolate the long-term trends from seasonal variations, local time, solar and magnetic activities. They applied their method to foF 2 data from Grahamstown station, getting a negative change for most hours and days. Yue et al. [5] also used a neural network method to derive long-term foF2 trends at 19 ionospheric ionosonde stations in the Asia/Pacific sector. They found different changes at these stations, with no pronounced diurnal and latitudinal effects in trends, and no uniform pattern of seasonal variation at most stations. Yue et al. stated that many factors, including the greenhouse effect, solar and geomagnetic activities, and neutral background gas, would influence the trends of ionospheric variation. Upadhyay and Mahajan [6] analyzed a global set of ionosonde stations, 
finding F2-layer parameters trends that were different in both sign and magnitude at different stations.

There are different trend results in these literatures, and these may be attributable to the different data resources and related data quality, different methods of correcting for the solar or geomagnetic changes, different analysis periods, or other factors.

In this paper, we use IRI-2007 empirical model to derive long-term foF 2 trends at the Moscow ionosonde station $\left(55.3^{\circ} \mathrm{N}, 37.3^{\circ} \mathrm{E}\right)$, and discuss possible origins of the results. We examine the relationships with the long-term trend and local time or season, and address the problem by analyzing data and figures. The paper is structured as follows. First, the data and method are presented; second, variations in the long-term slope trend are shown; last, possible mechanisms are discussed, especially geomagnetic activities and reversal or excursion of the earth's magnetic field.

\section{Data and method}

We obtained ionospheric foF2 data observed at Moscow ionosonde station, with a data interval from 1958 to 2007, covering almost five solar cycles. We use solar $10.7 \mathrm{~cm}$ radio flux (F10.7) as the solar activity index. The foF2 and F10.7 indexes were downloaded from the Space Physics Interactive Data Resource (http://spidr.ngdc.noaa.gov/ spidr/). The IRI-2007 (http://IRI.gsfc.nasa.gov) model developed by Bilitza [7] is used to remove solar and geomagnetic activities. This empirical model can capture the main tendency of the ionosphere changed by the solar activity. The Storm-time ionospheric correction model (STORM) [8] included in the IRI-2007 empirical model is an empirical correction, designed to capture changes in $\mathrm{F}$ region electron density during geomagnetic storms. Its output is used to scale the quiet time $f o F 2$, to account for the decreasing electron density during a geomagnetic storm. The IRI-2007 model input parameters can be chosen by geographic or geomagnetic coordinates, with the STORM turned on or off. Thus, we can identify four cases for discussing the longterm trends in foF 2: Case 1, geomagnetic coordinate, STORM turned off; Case 2, geomagnetic coordinate, STORM turned on; Case 3, geographic coordinate, STORM turned off; Case 4, geographic coordinate, STORM turned on. The International Geomagnetic Reference Field (IGRF) included in IRI-2007 calculates geomagnetic latitude and longitude by Definitive Geomagnetic Reference Field/ International Geomagnetic Reference Field (DGRF/IGRF) spherical harmonic coefficients during 1900-2015, at a 5 -year interval. The coefficients file was obtained from the National Geophysical Data Center (http://www.ngdc.noaa. gov/IAGA/vmod/igrf.html). The IGRF model will be used to obtain changes in the explanatory geomagnetic field elements, including the geomagnetic inclination angle $I$, geomagnetic angle $D$, and geomagnetic field strength $B$.
Different researchers used different approaches to extract long-term trends from ionospheric observations, with success depending largely on the method used. The useful "signal" is very small and "background" is very noisy, so special method is required to reveal a visible trend in observed foF 2 variations. Here, trends are analyzed for relative deviations in observed $f o F 2$ from the model:

$$
\delta f o F 2=\left(f o F 2_{\text {obs }}-f o F 2_{\text {mod }}\right) / f o F 2_{\text {obs }} \text {, }
$$

where $f o F 2_{\text {obs }}$ is the observation and $f o F 2_{\text {mod }}$ is attained by IRI-2007.

A linear regression fit can derive a linear trend:

$$
\delta \text { foF } 2=a+k \times \text { year, }
$$

where $k$ is the annual mean slope of diurnal variations.

\section{Results}

Ionospheric parameters are dominated by solar activity and influenced by geomagnetic conditions, so we examined these variables together. Figure 1 shows the daily F10.7 index, 3-hour values of Ap index, and ionospheric foF2. Figure 1(a) shows the solar activity over the past 50 years. It is seen that the standing time of rising phases is much longer than falling phases, which is much more obvious in solar cycles 20 and 23. It may be discerned from Figure 1(a) and (b) that the geomagnetic Ap index is modulated by the solar cycle, with intense geomagnetic activity corresponding to high solar levels, but with a lag of 1-2 years, and this is shown in Chaman-Lal [9]. From Figure 1(c), ionospheric foF 2 changes with local time and solar activity, and maximizes around 13-14 (LT), with the ratio of maximum value in solar maxima and minima around two.

The long-term trend of foF 2 was obtained by using the aforementioned method, and is presented in Figure 2. In Figure 2(a), the strong negative trend $\left(k=-15.2 \times 10^{-4}\right.$ per year) is evident, decreasing about $0.015 \mathrm{MHz}$ per year, and $0.76 \mathrm{MHz}$ over the past 50 years. However, the amplitude of the long-term trend in Figure 2(b) is markedly smaller ( $k$ $=-4.08 \times 10^{-4}$ per year), falling at about $0.2 \mathrm{MHz}$ over the past 50 years, thus demonstrating that the careful elimination of solar and geomagnetic activities and earth's magnetic field-induced variations are necessary to achieve reasonable trends.

Table 1 shows four results according to the different conditions. Clearly, foF2 variability is negative and very strong in Case 1. Comparing Cases 1 and 2, the correlation between observation and model increases from 0.91862 to 0.92831 , revealing that the long-term trend is influenced by the geomagnetic activity. Similarly, for Cases 1 and 3, and Cases 2 and 4, correlations are improved, suggesting that earth's magnetic field also affects the ionospheric variations. For the $k$ slope in Table 1, the rate of contribution of geomagnetic activity is about $60 \%$, and $15 \%$ for the variations in earth's magnetic field. Eliminating the aforementioned factors, the $\delta f o F 2$ trend is still negative, so there must be 

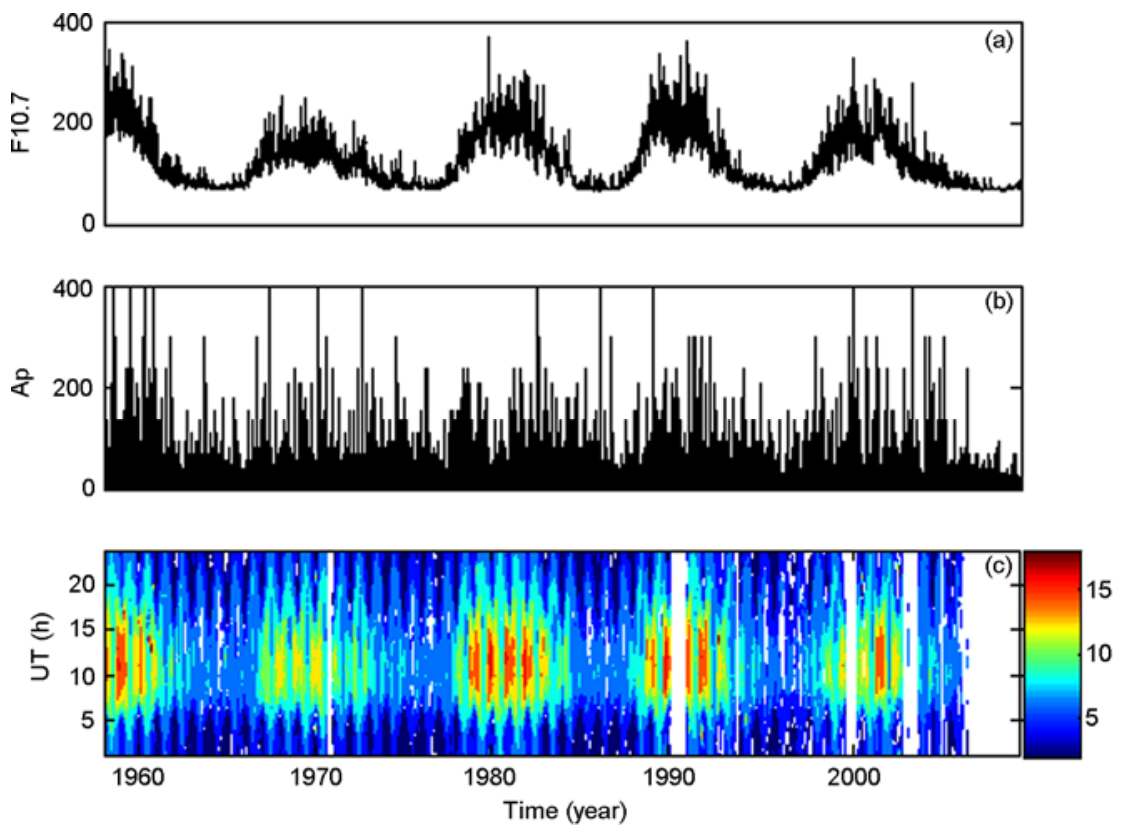

Figure 1 Daily F10.7, 3-hour values of Ap index and ionospheric foF2, during the period 1958 to 2007.

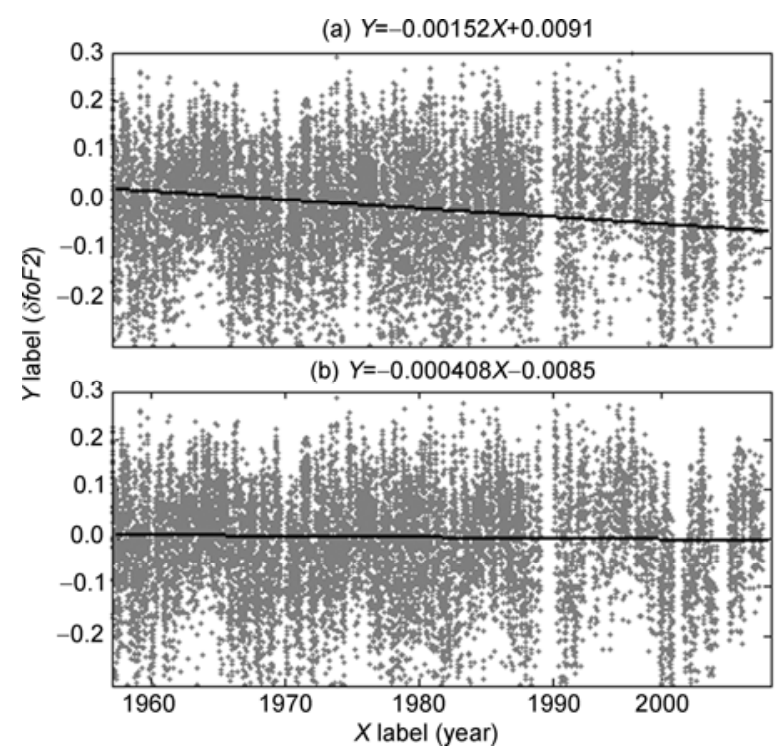

Figure $2 \delta f o F 2$ with time, for all times in Case 1 (a) and Case 4 (b), each with fitted linear regression lines.

Table 1 Correlation between observation and model, and the long-term trend $k \times 10^{4}$ per year (thick) for Cases 1 to 4

\begin{tabular}{ccc}
\hline & Geomagnetism location & Geography location \\
\hline STORM off & Case 1: 0.91862/-15.2 & Case 3: 0.92045/-13.3 \\
STORM on & Case 2: 0.92831/-5.7 & Case 4: 0.93009/-4.08 \\
\hline
\end{tabular}

other complex effects on the ionosphere. This will be discussed in Section 3.

Ionospheric $f o F 2$ varies with local time, so we presume that $\delta f \circ F 2$ does also vary. Figure 3 shows the trend values

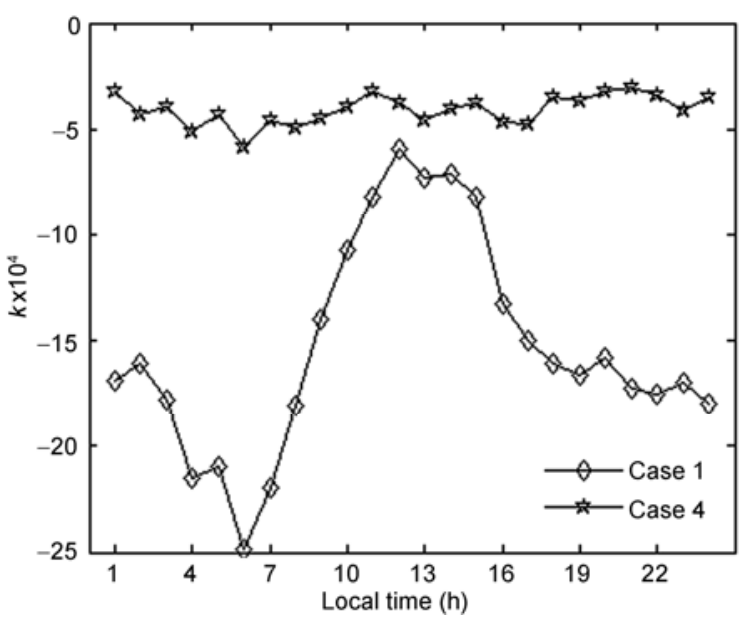

Figure 3 Value of the $f o \mathrm{~F} 2$ trend $k$ at Moscow ionosonde station versus local time. Diamonds and stars show results for Case 1 and Case 4.

obtained from the slope of the linear regression of $\delta f o F 2$ vs. local time. We can see from the figure that there is a stable negative trend when all the years are considered in Case 1, and there is a pronounced diurnal variation in $k$, with much larger values in the morning than during afternoon and evening. The maximum trend of about -0.0025 per year is at 06:00 LT, and the minimum of about -0.0006 per year is around 12:00 LT. Therefore, the maximum variation with local time is about four. There is no such result in Case 4. Possible reasons for this difference will be discussed in Section 3.

There is also seasonal variation in $f o F 2$, and $\delta f o F 2$ is believed to behave likewise. Figure 4 shows the annual variations in $k$ values. This picture demonstrates that there is 


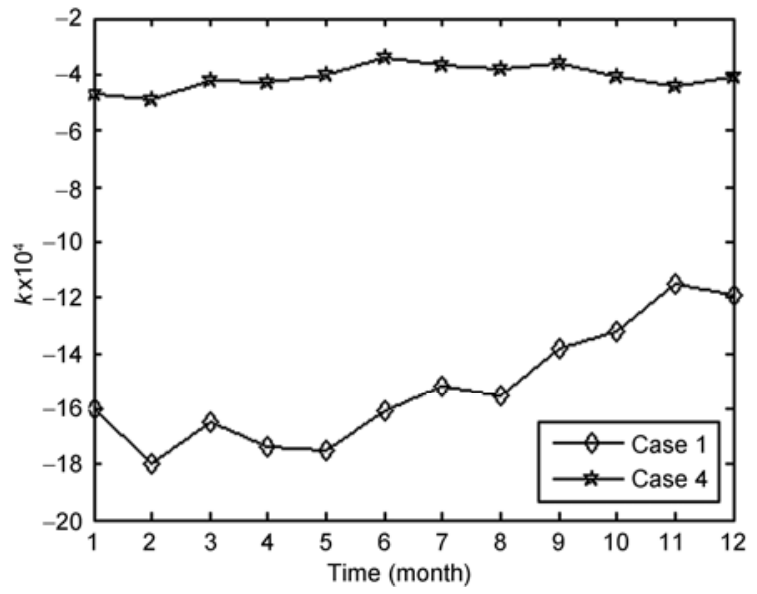

Figure 4 Same as Figure 3, but for the annual variations in $k$ slope.

seasonal variation in $k$ in Case 1 , but not so in Case 4. In Case 1 , the largest negative trend of about -0.0018 per year is observed in spring-summer, and the smallest trend of about -0.0012 per year is in winter. This gives a seasonal variation factor of 1.5. However, the value of $k$ is around $-4 \times 10^{-4}$ per year in Case 4. This will be addressed in Section 3.

Danilov and Mikhailov [10,11] indicated that only by selecting years around solar maxima or minima is possible to obtain stable significant trends, whereas for all years (including rising and falling phases of solar cycles) there is chaos, with various signs of trends. However, in our research (not detailed here), we found an obvious systematic effect using all available years, but only the years around solar maxima or minima failed to do so.

\section{Discussion and conclusions}

We used the IRI-2007 model and foF 2 data observed at the Moscow ionosonde station to derive long-term ionospheric trends, stratifying different conditions into four cases. The main results are as follows:

(1) Ionospheric foF2 varies with local time and solar activity, maximizing around 13-14 (LT), with the ratio of maximum value in solar maxima and minima around two.

(2) A significant negative trend $\left(k=-15.2 \times 10^{-4}\right.$ per year) was found in Case 1 , decreasing at about $0.015 \mathrm{MHz}$ per year, and $0.76 \mathrm{MHz}$ over the past 50 years. The amplitude of the residual long-term trend of Case 4 is markedly smaller $\left(k=-4.08 \times 10^{-4}\right.$ per year), declining about $0.2 \mathrm{MHz}$ over the past 50 years.

(3) There is a pronounced diurnal variation in $k$, with much larger values in the morning than during afternoon and evening, with a maximum negative trend around 06:00 LT. The magnitude of variation vs. local time is about four. For Case 4, however, there are no such features.

(4) In Case 1, the largest negative trend is observed in spring-summer and the smallest trend in winter. The maxi- mum factor of seasonal variation is about 1.5 . The value of $k$ is around $-4 \times 10^{-4}$ per year for Case 4 .

The trend is very small. Nevertheless, the result is interesting from a physical point of view, indicating that $f_{o F}$ long-term variation may be attributed to natural or manmade origins. There have been many interpretations of the observed foF 2 trends. According to Rishbeth [12,13], the increase of $\mathrm{CO}_{2}$ and $\mathrm{CH}_{4}$ mixing ratios in the lower thermosphere should cause long-term variation in ionospheric parameters. This has been simulated by Qian [14]. It is known that the most important processes controlling the ionosphere are photochemistry and dynamical processes. The former process has been removed by isolating solar activity, so what remains is the latter. Different dynamical mechanisms could be responsible for the ionospheric long-term effect. These include the connection between magnetopause position and ionospheric ionization level $[15,16]$, planetary waves and quasi-biennial oscillation of the semidiurnal tide $[17,18]$, long-term decreases of the horizontal thermospheric wind [19], long-term increase or decrease of geomagnetic activity [20], enhancement of magnetic storms [21], and variations in the geomagnetic field [22]. We present our investigation of this problem in the following.

As mentioned above, the $k$ slope varies with local time, and this may be associated with the variability of diurnal ionospheric storms. The $\delta f o F 2$ correlation with Ap also works in the same direction (Figure 5). The strongest negative correlation (about -0.5 ) is in the early morning, and the weakest negative correlation (about -0.27 ) occurs during noontime. These are similar to the distributions of $k$ slope in Case 1 (Figure 3). This means that ionospheric storms at the Moscow station, induced by geomagnetic storms, are mostly negative. The principal pattern of an ionospheric storm is as follows. Joule heating in the auroral zone changes the thermospheric composition, increasing the neutral gas temperature and generating storm-induced circulation. Changes in aeronomical parameters $\left(\left[\mathrm{N}_{2}\right] /[\mathrm{O}]\right.$ and $\left.T\right)$ can decrease electron concentration in the heated gas. This is the negative

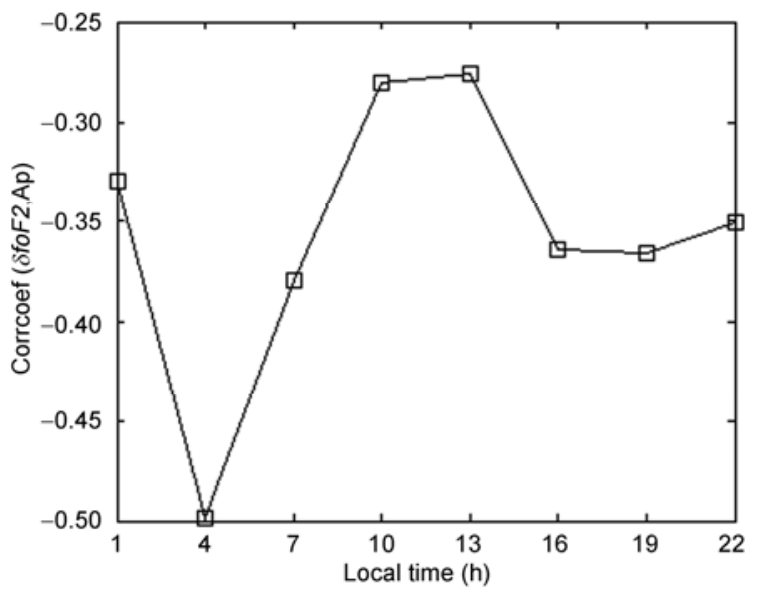

Figure 5 Diurnal variations in correlation coefficient $r$ ( $\delta f \circ F 2$, Ap). 
phase of an ionospheric storm. The storm-induced circulation tends to transport the heated gas from the auroral zone to lower latitudes. Meanwhile, negative F2-layer storm effects are known to be the strongest in the post-midnight to early-morning LT period, and weaker in the afternoon $[23,24]$. Apparently, the effects found here are related to the thermospheric winds. This is because of the disturbed neutral composition with decreased $[\mathrm{O}] /\left[\mathrm{N}_{2}\right]$ ratio, which is advected toward middle latitudes during the night, but shifts to higher latitudes via the diurnally varying thermospheric circulation in the daytime $[25,26]$. Therefore, negative ionospheric storms will affect the long-term trends in ionospheric foF 2 .

There is also a pronounced seasonal effect shown in Figure 4, with a greater trend in spring-summer than in winter. In the work of Danilov [10,11] and Mikhailov [20], $\delta h m F 2$ features can be interpreted as the terms of long-term variations in geomagnetic activity, and related changes in the number or intensity of ionospheric storms. Consequently, we believe that the long-term trends of foF 2 are somewhat related to the geomagnetic storms. The seasonal dependence may be a manifestation of the same process, because it is well known that there is seasonality in the occurrence and development of ionospheric storms [27]. Figure 6 encourages the assumption that magnetic mechanisms influence the seasonal long-term foF 2 trends. In December, there are fewer geomagnetic storms than in other months, as displayed in Figure 6. According to our knowledge, ionospheric storms have seasonal aspects related to thermospheric winds. Storm-induced and normal circulations depend on the season. During winter daytime, the solar-driven circulation is oriented poleward, opposite to the storminduced circulation. In this case, the heated gas may remain "locked" in the zone of Joule heating, or drift only slightly toward middle latitudes. The situation is different at night, when the solar-driven background circulation weakens and cannot completely stop the storm-induced circulation. Then, the gas with altered temperature and composition moves

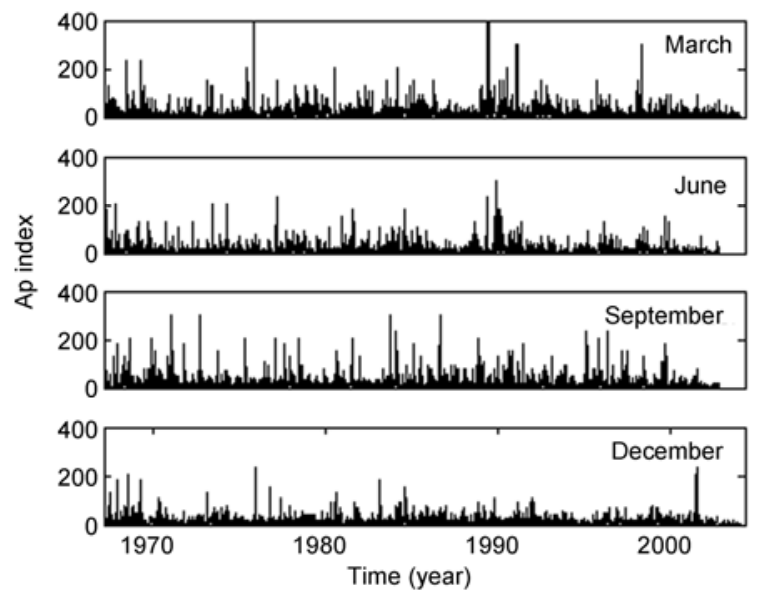

Figure 6 Seasonal variations in geomagnetic activity. toward the lower latitudes, and the negative phase is observed at relatively low regions. In summer, the storm- induced and solar-driven background circulations coincide almost all day, and thus the heated gas reaches lower latitudes. As a whole, the seasonal trend of $f o F 2$ can be explained by seasonal changes in geomagnetic activity or storms.

According to Table 1, the results are sensitive to changes in geomagnetic field elements using the IGRF model. Therefore, there is some speculation about possible correlation between the ionospheric long-term trends and the excursion of earth's magnetic field. For the fixed Moscow station, its geomagnetic field parameters, including $I, D$ and $B$, have secular variations, which can be simulated by the IGRF. Annual variations in $I, D$ and $B$ are $1.3 \mathrm{~min} /$ year, 6.4 $\mathrm{min} /$ year and $-6.1 \mathrm{nT} /$ year, respectively.

Several researchers $[5,28-30]$ have shown that these secular variations result in long-term variation in the effects of the neutral wind or electric field on the ionospheric parameters. According to the continuity, momentum and temperature equations, we obtain

$$
V_{z}=f(I, D, B, U)
$$

where $V_{z}$ is the vertical drift of plasma and $U$ is the horizontal thermospheric wind. Elias [30] and Yue [22] pointed out that the horizontal thermospheric wind $U$ drives the ionospheric plasma along geomagnetic lines at speed $U \cos I$, and that the vertical component of the thermospheric wind, $U \sin I \cos I$, can raise or lower the height of the ionosphere, thereby increasing or decreasing plasma density. Furthermore, the amplitude of the component of thermospheric wind in the direction of the geomagnetic field is controlled by $D$, and this may also affect the ionosphere [31]. Therefore, the neutral meridional wind $U$ drives the plasma along geomagnetic lines at speed $U \cos D \cos I$, and in the vertical direction at $U \cos D \sin I \cos I$. Yue et al. [22] used a theoretical model to assess effects of the secular variations in geomagnetic field orientation on ionospheric long-term trends (details not given here). We know that $\vec{E} \times \vec{B}$ influences the height and plasma density of the ionosphere, $(\vec{E}$ is the electric field). Thus the variation in $\vec{B}$ will influence longterm trends of ionospheric parameters, including foF 2 . The excursion of the geomagnetic field is simulated by the empirical model. De Santis [32] and Gubbins [33] have demonstrated that the earth's magnetic field has had an excursion in past ten years. As a result, we suggest that the excursion of earth's magnetic field may induce long-term foF 2 variations.

Other factors may also shape long-term foF 2 trends. According to Dickinson [34], the cooling ratio of $\mathrm{CO}_{2}$ can be expressed as

$$
\begin{aligned}
& L_{\mathrm{CO}_{2}}= 2.65 \times 10^{-20}\left\{A\left(\left[\mathrm{O}_{2}\right]+\left[\mathrm{N}_{2}\right]\right)\right. \\
&+B[\mathrm{O}]\}\left[\mathrm{CO}_{2}\right] \exp \left(-960 / T_{n}\right), \\
& A=2.5 \times 10^{-21} \max \left(1+0.03\left(T_{n}-200\right), 1\right), \\
& B=1.0 \times 10^{-18} \max \left(T_{n} / 300,1\right),
\end{aligned}
$$


where $\left[\mathrm{O}_{2}\right],\left[\mathrm{N}_{2}\right]$ and $\left[\mathrm{CO}_{2}\right]$ denote the densities of $\mathrm{O}_{2}, \mathrm{~N}_{2}$ and $\mathrm{CO}_{2} ; T_{n}$ is the thermospheric temperature. So we find that if the other parameters are fixed, greater $\left[\mathrm{CO}_{2}\right]$ leads to more $L_{\mathrm{CO}_{2}}$, and the cooling temperature will reflect the long-term trend variations in the ionosphere. The increase of $\mathrm{CO}_{2}$ will not only cool the thermosphere temperature, but also recombine electron particles as follows [35]:

$$
\begin{aligned}
& \mathrm{CO}_{2}+\mathrm{O}^{+} \rightarrow \mathrm{O}_{2}^{+}+\mathrm{CO} \\
& \mathrm{O}_{2}^{+}+\mathrm{e} \rightarrow \mathrm{O}^{*}+\mathrm{O}^{* *}
\end{aligned}
$$

In the lower ionosphere (about $100-120 \mathrm{~km}$ ), $\mathrm{CO}_{2}$ almost vanishes [36], and there is a recombination loss of ions. So electron density will be affected, producing the long-term ionospheric variations.

Morphological features of the $f_{o} F 2$ trends revealed here can be explained by many causes, either natural or manmade. We need more work on this problem to expand the current research.

The authors thank SPIDR for providing the foF 2 data, and two anonymous referees for their help in evaluating this paper. This work was supported by the National Natural Science Foundation of China (40890162 and 40505005) and the Specialized Research Fund for State Key Laboratories.

1 Roble R G, Dickinson R E. How will changes in carbon dioxide and methane modify the mean structure of the mesosphere and thermosphere? Geophys Res Lett, 1989, 16: 1441-1444

2 Danilov A D, Mikhailov A V. Spatial and seasonal variations of the foF2 long-term trends. Ann Geophys, 1999, 17: 1239-1243

3 Danilov A D, Mikhailov A V. Long-term trends of the F2-layer parameters: A new approach. Int J Geomag Aeron, 1999, 1: 3, http://eos.wdcb.rssi.ru/ijga

4 Poole A W V, Poole M. Long-term trends in foF2 over Grahamstown using neural network. Ann Geophys, 2002, 45: 155-161

5 Yue X, Wan W, Liu L, et al. Applying artificial neural network to derive long-term foF2 trends in the Asia/Pacific sector from ionosonde observations. J Geophys Res, 2006, 111: A10303

6 Upadhyay H O, Mahajan K K. Atmospheric greenhouse effect and ionospheric trends. Geophys Res Lett, 1998, 25: 3375-3378

7 Bilitza D, Reinisch B W. International reference ionosphere 2007: Improvements and new parameters. Adv Space Res, 2008, 42: 599-609

8 Fuller-Rowell T, Araujo-Pradere E, Condrescu M. An empirical ionospheric storm-time ionospheric correction model. Adv Space Res, 2000, 8: 15-24

9 Chaman-Lal. Sun-Earth geometry, geomagnetic activity and planetary F2 layer ion density, Part I: Signatures of magnetic reconnection. J Atmos Solar Terr Phys, 2000, 62: 3-16

10 Danilov A D, Mikhailov A V. Long-term trends of the F2-layer critical frequencies: A new approach. In: Proceedings of the 2nd COST 251 Workshop "Algorithms and Models for COST 251 Final Product”, Rutherford Appleton Laboratory, UK, 1998. 114-121

11 Danilov A D, Mikhailov A V. Spatial and seasonal variations of the foF2 long-term trends. Ann Geophys, 1999, 17: 1239-1243

12 Rishbeth H, Roble R G. Cooling of the upper atmosphere by enhanced greenhouse gases - Modelling of the thermospheric and ionospheric effects. Planet Space Sci, 1992, 40: 1011-1026
13 Rishbeth H. A greenhouse effect in the ionosphere? Planet Space Sci, 1990, 38: 945-948

14 Qian L, Solomon S C, Roble R G, et al. Model simulations of global change in the ionosphere. Geophys Res Lett, 2008, 35: L07811

15 Makarova L N, Shirochkov A V. The magnetopause position as an indicator of the ionisation level in the dayside high latitude ionosphere. Radio Sci, 1998, 33: 1877-1884

16 Wang C R, Zong Q G, Wang Y F. Propagation of interplanetary shock excited ultra low frequency (ULF) waves in magnetosphereionosphere-atmosphere-Multi-spacecraft "Cluster" and groundbased magnetometer observations. Sci China Tech Sci, 2010, 53: 2528-2534

17 Jarvis M. Quasi-biennial oscillation effects in the semidiurnal tide of the Antarctic lower thermosphere. Geophys Res Lett, 1996, 23: 2661-2664

$18 \mathrm{Mu}$ W F, Wan W X, Ren Z P, et al. Correlation between ionospheric longitudinal harmonic components and upper atmospheric tides. Chin Sci Bull, 2010, 55: 4037-4045

19 Jarvis M J, Jenkins B, Rodgers G A. Southern hemisphere observations of long term decrease in $\mathrm{F}$ region altitude and thermospheric wind providing possible evidence for global thermospheric cooling. J Geophys Res, 1998, 103: 29774-29787

20 Mikhailov A V, Marin D. Geomagnetic control of the foF2 long-term trends. Ann Geophys, 2000, 18: 653-665

21 Clilverd M A, Clark T D G, Clarke E, et al. Increased magnetic storm activity from 1868 to 1995. J Atmos Solar-Terr Phys, 1998, 60: 1047-1056

22 Yue X, Liu L, Wan W, et al. Modeling the effects of secular variation of geomagnetic field orientation on the ionospheric long term trend over the past century. J Geophys Res, 2008, 113: A10301

23 Wrenn G L, Rodger A S, Rishbeth H. Geomagnetic storms in the Antarctic F-region. I. Diurnal and seasonal patterns for main phase effects. J Atmos Terr Phys, 1987, 49: 901-913

24 Prölss G W. On explaining the local time variation of ionospheric storm effects. Ann Geophys, 1993, 11: 1-9

25 Fuller-Rowell T J, Codrescu M V, Moffett R J, et al. Response of the and ionosphere to geomagnetic storm. J Geophys Res, 1994, 99: 3893-3914

26 Liu L, Wan W, Chen Y, et al. Solar activity effects of the ionosphere: A brief review. Chin Sci Bull, 2011, 56: 1202-1211

27 Prölss G W. Ionospheric F-region storms. In: Handbook of Atmospheric Electrodynamics. 2nd ed. Boca Raton: CRC Press, 1995. 195-248

28 Ulich T, Turunen E. Evidence for long-term cooling of the upper atmosphere in ionosonde data. Geophys Res Lett, 1997, 24: 1103-1106

29 Foppiano A J, Cid L, Jara V. Ionospheric long-term trends for South American mid-latitudes. J Atmos Sol Terr Phys, 1999, 61: 717-723

30 Elias A G, de Adler N O. Earth magnetic field and geomagnetic activity effects on long-term trends in the F2 layer at mid-high latitudes. J Atmos Sol Terr Phys, 2006, 68: 1871-1878

31 Heelis R A. Electrodynamics in the low and middle latitude ionosphere: A tutorial. J Atmos Sol Terr Phys, 2004, 66: 825-838

32 De Santis A. How persistent is the present trend of the geomagnetic field to decay and, possibly, to reverse? Phys Earth Planet Int, 2007, 162: $217-226$

33 Gubbins D, Jones A L, Finlay C C. Fall in Earth's magnetic field is erratic. Science, 2006, 312: 900-902

34 Dickinson $\mathrm{R}$ E. Infrared radiative cooling in the mesosphere and lower thermosphere. J Atmos Terr Phys, 1984, 46: 995-1008

35 Bernhardt P A. Chemistry and dynamics of SF6 injection into the F region. J Geophys Res, 1984, 89: 3929-3937

36 Akmaev R A, Fomichev V I. A model estimate of cooling in 1595 the mesosphere and lower thermosphere due to the $\mathrm{CO}_{2}$ increase over the 1596 last 3-4 decades. Geophys Res Lett, 2000, 27: 2113-2116

Open Access This article is distributed under the terms of the Creative Commons Attribution License which permits any use, distribution, and reproduction in any medium, provided the original author(s) and source are credited. 